\title{
Announcements
}

Published online: 18 May 2016

(C) International Association of Medical Science Educators 2016

\author{
AMEE 2016 \\ Barcelona, Spain August 27-31, 2016
}

The AMEE annual conference is now established as the key meeting for all involved in medical and healthcare professions education including teachers, educationists, researchers, administrators, and students. There will be something for everyone - those new to education or with wide experience; those interested in undergraduate education, postgraduate training or CPD; those working in medicine or other healthcare profession as a teacher, student, administrator, researcher, or leader. Visit http://amee.org/ conferences/amee-2016 for more information.

\section{OMED 2016}

Anaheim, California, USA September 16-20, 2016

With inspiring general sessions, cutting-edge CME, and networking opportunities galore, OMED 2016 promises to be an incredible event. Meet and connect with your peers, colleagues, and friends at the largest gathering of DOs in the world.

43rd Annual National Conference on Professional Nursing Education and Development: Bridging Generations in Nursing: Infusing Creativity and Collaboration into Professional Development

Columbus, Ohio, USA, October 20-23, 2016

The Professional Nurse Educator Group (PNEG) is a virtual network of educators from all over the USA that are dedicated to the lifelong learning of professional nurses. This network is open to all educators in the field and includes faculty from nursing schools, continuing nursing education professionals, entrepreneurs, and nursing staff development professionals.
The Generalists in Medical Education Conference Seattle, Washington, USA, November 10-11, 2016

The Annual Generalists in Medical Education conference will be held Thursday, November 10, and Friday, November 11, 2016, in Seattle, Washington, USA. The Generalists in Medical Education is successful because of your interest in attending the conference and your willingness to share professional accomplishments and educational research. For more information, visit the Generalists in Medical Education website: www.thegeneralists.org/conference.

2016 AAMC Annual Meeting and Medical Education Meeting Seattle, Washington, USA, November 11-15, 2016

Learn Serve Lead: The AAMC Annual Meeting and the AAMC Medical Education Meeting will take place in Seattle on November 11-15, 2016. The meetings will integrate sessions on medical education throughout and feature more in-depth programming on medical education, research, and innovation during focused days of content. See https://www.aamc.org.

\section{NVMO meeting}

Egmond aan Zee, The Netherlands, November 17-18, 2016.

The annual meeting of the Netherlands Association for Medical Education (NVMO) will take place in Hotel Zuiderduin, Egmond aan Zee, The Netherlands. See www. nvmo.nl for more information on NVMO.

Save the dates:

- 2017 APMEC Conference, Singapore, January 11-15, 2017

- AACOM \& AODME Joint Annual Conference, Baltimore, Maryland, USA, April 26-29, 2017 